\title{
Fisioterapia na promoção da saúde com foco no desenvolvimento neuropsicomotor
}

Francieli Bonetto

Julie Brusamarello

Franciane B. Fiório

Sidiane Basso

Michele Minozzo dos Anjos

CADERNO DE RESUMOS

FisiSenectus. Unochapecó Ano 1 - Edição especial - 2013 p. 134

Francieli Bonetto, acadêmica do Curso de Graduação em Fisioterapia da Universidade Comunitária da Região de Chapecó (Unochapecó), francieli.b@unochapeco.edu.br

\section{Resumo}

Introdução: O desenvolvimento infantil relaciona-se com a maturação neurológica, através de condutas executadas pela criança, decorrente do aprendizado e da aquisição de habilidades e aptidões que as possibilitam enfrentar os desafios na vida adulta, tornando-se adolescentes e adultos produtivos e capazes de inserir-se na sociedade. Objetivos: Este estudo tem o objetivo de apresentar e discutir o projeto de extensão Fisioterapia na Promoção da Saúde, vinculado ao Programa de Atendimento a Crianças e Adolescentes, da Unochapecó, que busca proporcionar às crianças e adolescentes o conhecimento sobre o desenvolvimento neuropsicomotor e orientar sobre o cuidado em saúde e bons hábitos de vida, capacitando-os para serem multiplicadores de informações sobre o corpo humano saudável. Metodologia: O projeto de extensão Fisioterapia na Promoção da Saúde é desenvolvido por quatro estudantes bolsistas e três docentes do curso de Fisioterapia, em que são atendidas, semanalmente, aproximadamente 60 crianças e adolescentes, divididos em dois grupos de acordo com a faixa etária (6 a 10 e 11 a 14 anos), nos quais são realizadas oficinas com foco no desenvolvimento neuropsicomotor compreendendo temas como coordenação motora, equilíbrio, esquema corporal, motricidade fina e ampla. Após a realização todas as oficinas foram relatadas em diário de campo e a análise de conteúdo foi realizada conforme proposição de Minayo (2010). Resultados: As oficinas desenvolvidas de forma lúdica e recreativa contribuíram significativamente para o interesse e a participação, no qual os participantes demonstraram fácil compreensão e levantamento de discussões sobre os assuntos abordados. Dessa forma, estes puderam não apenas vivenciar as atividades, mas serem multiplicadores do conhecimento às pessoas de seu convívio social e com a prática puderam melhorar suas habilidades motoras, como mencionado por estes.

Considerações finais: É importante destacar que o desenvolvimento neuropsicomotor abrange várias habilidades motoras e estas devem ser aperfeiçoadas ao longo do crescimento e desenvolvimento. Devemos considerar que alguns atrasos motores podem ocorrer durante o desenvolvimento e acarretar prejuízos que podem se estender até a fase adulta; através das intervenções sugere-se que a prática dessas atividades durante a infância e adolescência venham otimizar o desenvolvimento neuropsicomotor.

\section{Palavras-chave}

Desenvolvimento neuropsicomotor. Crianças. Fisioterapia. 